\title{
Open locked nailing using an expandable nail - an alternative approach
}

\begin{abstract}
Objective: The main objective is to evaluate various outcomes of open intramedullary nailing using the Fixion expanding nail at our institution.

Method: A retrospective study was performed using the hospital records. The mechanism of injury, the time between injury and surgery, blood transfusion requirements, blood loss, surgical times, time taken to weight bear (for the femoral/ tibial fractures), time for commencement of upper limb use (for humeral fractures), complication rates and the average follow up times were documented. Fifty-seven long bone fractures in 57 patients were included in this study. Complete results including preoperative X-Rays were available for 27 patients. In 30 cases, the actual X-Rays were not located but documentation by the treating surgeons was available.
\end{abstract}

Results: There were 44 acute femoral fractures, 6 acute tibial fractures, 3 acute humeral fractures, 2 humeral nonunion, 1 tibial nonunion and 1 pathological femoral fracture. All patients achieved radiological union and the complication rates were deemed acceptable.

Conclusion: Open intramedullary nailing using an expanding nail may be used for a variety of indications involving the humerus, tibia and femur.

Keywords: Expandable, Open, Fixion, Intramedullary, Fractures, Locked nailing
Volume I Issue I - 2014

\author{
Cary K Fletcher,' McDowell D,' Naparla C'2 \\ 'Department of Orthopaedic, St.Ann's Bay Hospital, NERHA, \\ Jamaica \\ 2Department of Radiology, St. Ann's Bay Hospital, NERHA, \\ Jamaica
}

Correspondence: Cary Fletcher, St. Ann's Bay Hospital, North East Regional Health Authority, 4 Sunflower Drive, Discovery Bay, St. Ann, Jamaica, Tel 876-383-1273,

Email c.fletch30@yahoo.com

Received: May 24, 2014 | Published: July 03, 2014
Abbreviations: Avg, Average; mL, milliliters; cm, Centimeters; mm, millimeters; Mins, Minutes; AO, Arbeitsgemeinschaft für Osteosynthesefragen; M, Male; F, Female; MVA, Motor Vehicle Accident; NB, Note Well; PWB, Partially Weight Bearing; FWB, Fully Weight Bearing; OTA, Orthopaedic Trauma Association

\section{Introduction}

For acute femoral shaft fractures, the Fixion nail is indicated for use in fractures at least $5 \mathrm{~cm}$ distal to the surgical neck and 5 $\mathrm{cm}$ proximal to the distal end of the medullary canal. Three of the patients in this study however, had subtrochanteric fractures. The nail is made of stainless steel with a solid cylindrical core consisting of 4 longitudinal peripheral bars connected radially by thin membranes. The proximal end has a 1 way valve to maintain the inflation. A pump is manually filled with normal saline or sterile water by placing the end of its tubing at the bottom of the fluid filled container and then turning its $\mathrm{T}$ handle counterclockwise. The pressure gauge is held upright while filling the pump. Removal of air in the inflating system is then ensured..$^{1-4}$ by removing the tubing from the fluid filled container and holding it upright after which the $\mathrm{T}$ handle is turned clockwise to release a few drops of fluid from the end of the pump. The driver handle is attached to the pump and again the fluid is released at the tip of the driver handle. The driver handle assists in the insertion of the nail and acts as a conduit for the saline or sterile water. The nail is passed across the fracture site in its reduced diameter. This allows for easy passage across the fracture site thereby reducing the surgical time. ${ }^{5}$ The hand pump is then used to inflate the nail once it is in the appropriate position across the reduced fracture site. ${ }^{1,3}$ Unlike most authors, sterile water was used in this study to facilitate inflation. The four external bars are forced against the endosteal surface of both cortical and cancellous bone. This allows for the nail to adapt to the native endosteum throughout its length for the more stable fracture patterns. The abutment of the 4 bars against the endosteum provides fracture fixation via a self locking mechanism. These bars provide rotational stability, and the large frictional area allows for pressure to be evenly distributed throughout the nail. This is in contrast to interlocking nails which rely mainly on interlocking screws for axial and rotational stability. In this case, most of the strain is on the interlocking screws. A pressure gauge allows for continuous monitoring of pressure during inflation. ${ }^{6}$

\section{Material and methods}

The data was collected retrospectively by reviewing the medical records of all patients who had undergone open intramedullary nailing for femoral, tibial and humeral fractures at this institution. The 57 patients included in the study all had the following documentation in their medical records: the mechanism of injury, the time between injury and surgery, blood transfusion requirements, blood loss, time taken to weight bear (for the femoral/tibial fractures), time for commencement of upper limb use (for humeral fractures), complication rates and the average times of follow up. Any patient who did not have all of these parameters recorded in their notes were excluded from the study.

Preoperative radiographs for 30 patients could not be located at the time of performing this study. For these patients, we relied on the documentation of a member of the admitting orthopedic team. From the documentations, the fracture pattern was mentioned in each case but not classified using the AO system. For the comminuted fractures, it was mentioned whether or not the comminution was mild or severe. Based on the description of the preoperative films and review of 
the postoperative radiographs by the authors, a relatively accurate assessment of the fracture pattern was made. Where the description of the fracture pattern was deemed inadequate, the case was not considered for the study. An independent Radiologist examined the $\mathrm{X}$-rays for the remaining 27 patients. For these patients, the AO classification was used. Due to the lack of a fracture table and a C-arm, all procedures were performed open. All patients received a single dose of intravenous antibiotics just prior to incision. All but 1 patient with lower limb fractures had spinal anesthesia. Hand reaming was performed to allow for passage of the nail in cases where the canal was narrower than the diameter of the nail. In those cases, reaming was done to $1 \mathrm{~mm}$ greater than the diameter of the nail. Monitoring of the fracture site during inflation of the nail was done under direct vision.

\section{Results}

From the period August 2008 to August 2013, we performed open intramedullary nailing on 57 patients with long bone injuries using the Fixion expandable nail. The breakdown of the AO classification identified A2, A3, B2, B3, C1, and C3 subtypes (Table 1). The femoral shaft was the commonest site of injury for the acute traumatic fractures. Nonunion accounted for $6 \%$ of all injuries (Figure 1). Males outnumbered females to a ratio of 46:11. The age ranged from 18-90 years, with a mean age of 38 years. Motor vehicle accidents accounted for majority of the cases (Figure 2). Nineteen patients had concomitant injuries, the commonest of which was mild head injury. Ninety-eight percent of all injuries were closed. The time of surgery varied, with the time between injury and surgery being 2-213 days (average 17.8 days). The patient who waited 213 days for surgery had defaulted from the outpatient department and subsequently presented again. Surgery time also varied, with femoral cases accounting for 102 mins, tibial 120 mins, and humeral 250 mins; this also accounted for 36, 5, and 4 patients respectively. The mean blood loss was $120 \mathrm{~mL}, 250 \mathrm{~mL}$, and $400 \mathrm{~mL}$, for the tibial, humeral, and femoral fractures respectively. The excluded patients for the reporting of surgical time were due to the fact that they had other surgical procedures in the same sitting and the actual time taken for the Fixion nailing could not be ascertained from the notes. Preoperatively 8 patients received blood transfusion at an average of 2.25 units. Postoperatively 6 patients were transfused at a rate of 2.8 units. Three of the 6 patients who were transfused preoperatively, was also transfused postoperatively. The patients were allowed to PWB with crutches when there was evidence of adequate callus formation. Regardless of the fracture pattern, immediate weight bearing was not allowed. Full weight bearing (FWB) was allowed when there was at least 3 out of 4 healed cortices. For humeral fractures, range of motion exercises of the adjacent joints were allowed 2 weeks postoperatively and manual work was permitted after 3 months. For the femoral fractures, PWB was commenced at an average of 7.8 weeks whereas for the tibial fractures it was commenced at 9.5 weeks. FWB was commenced at an average of 14.2 weeks in the patients with femoral fractures in comparison to 16 weeks in the patients with tibial fractures. All of the humeral fractures in this study demonstrated advanced callus at an average of 12.3 weeks. The mean follow up time for all patients was 44.6 months (6-70 months). There were no cases in which the nail was damaged, no cases of iatrogenic fractures, or disorders of union. The medical records of the 57 patients in the study clearly stated that all of the fractures healed with no evidence of malrotation, angulation or shortening. All of the nails expanded. There were 2 superficial infections and 1 deep infection. Both superficial infections resolved with intravenous antibiotics. The patient who had a deep infection returned to the operating theatre and had nail removal, reaming and Gentamicin bead placement. After removal of the beads, his biochemical markers normalized and he did clinically well thereafter. One patient who had bilateral tibial shaft fractures developed a pulmonary embolus postoperatively. He was successfully treated with Warfarin. We had 1 case of radial nerve palsy. On revision the nerve was found to be entrapped under a circlage wire. This patient to date had full recovery of radial nerve function post wire removal. All the other patients treated with circlage wiring had femoral fractures (Table 2). Nine patients requested nail removal after having persistent limb discomfort for at least 3 months postoperatively ( 5 femurs, 3 tibiae and 1 humerus). Five of these patients subsequently had nail removal because a definite cause was identified i.e. a proud implant. All 5 patients eventually had less pain post procedure.

Table I Breakdown of the AO classification in the patients

\begin{tabular}{lll}
\hline HUMERUS & 3 pts & \\
\hline & A2 & I \\
FEMUR & CI & 2 \\
& 21 pts & \\
& A2 & 6 \\
& A3 & 5 \\
& B2 & 1 \\
TIBIA & B3 & 7 \\
& C3 & 2 \\
& 3 pts & \\
& A2 & 1 \\
& A3 & 1 \\
& C3 & 1 \\
\hline
\end{tabular}

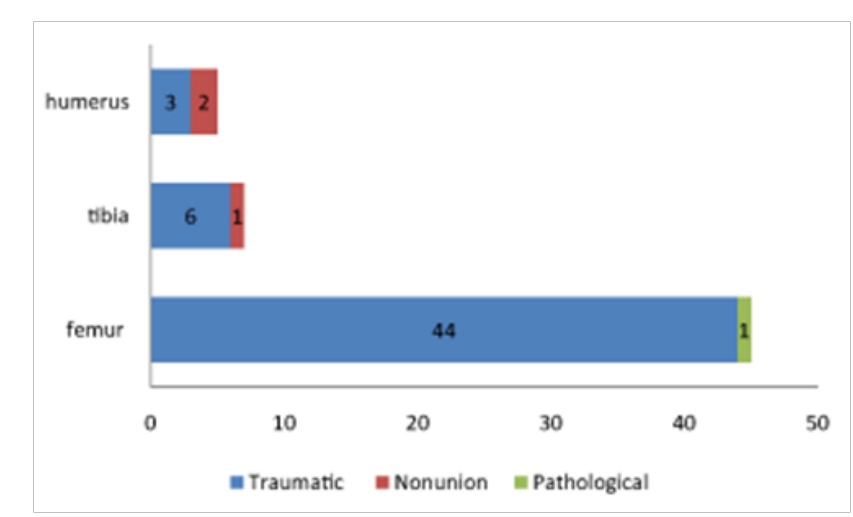

Figure I $N=57$; Epidemiological distribution of the pathological fractures, traumatic fractures, and nonunion.

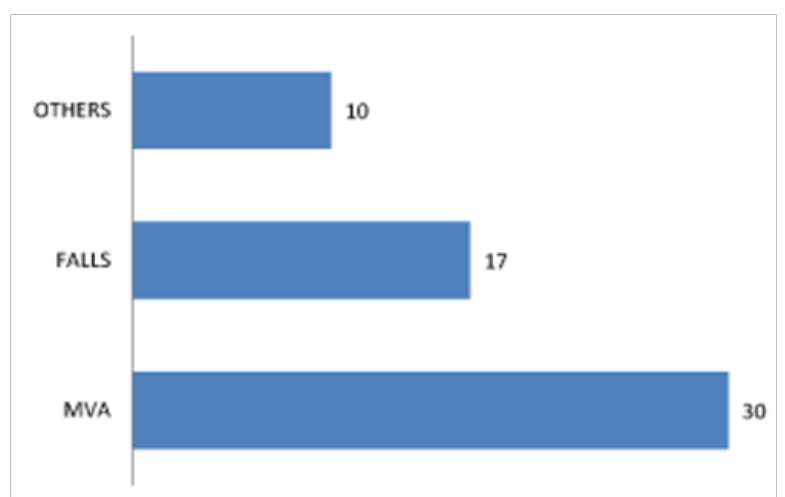

Figure 2 Etiology of the injuries was blunt trauma, with MVA accounting for majority, followed by falls and others respectively. The majority of the falls were low energy. 
Table 2 The cases that had circlage wiring was $7(\mathrm{~N}=7)$. The mechanisms of injuries were MVA, falls, and others; where MVA accounted for 3 and falls and others accounted for 2 each. X-ray findings ranged from mild to significant comminution. The presence of other injuries was 2; I each for MVA and others. Only 3 of the cases needed blood transfusion, and the transfusion was administered before, after or both combined. The average time for surgery from the time of injury ranged from 5.7 to 16 . The average blood loss was $933 \mathrm{ml}$ to $1350 \mathrm{ml}$. The average surgical times ranged from 95 minutes to 156.7 minutes. The average days spent on the ward post surgery ranged from 6.5 to 8 days. The time taken to PWB ranged from 8 to 12.5 weeks and FWB ranged from I 3 to I5.5 weeks

\begin{tabular}{llllllllll}
\hline $\begin{array}{l}\text { Mechanism } \\
\text { of Injury }\end{array}$ & $\begin{array}{l}\text { X-Ray } \\
\text { Findings }\end{array}$ & $\begin{array}{l}\text { Other } \\
\text { Injuries }\end{array}$ & $\begin{array}{l}\text { Blood } \\
\text { Transfusion } \\
\text { Amount }(\mathbf{m l})\end{array}$ & $\begin{array}{l}\text { Average Time } \\
\text { to } \\
\text { Surgery } \\
\text { (days) }\end{array}$ & $\begin{array}{l}\text { Blood } \\
\text { Loss } \\
(\mathbf{m l})\end{array}$ & $\begin{array}{l}\text { Surgery } \\
\text { Time } \\
(\mathbf{m i n})\end{array}$ & $\begin{array}{l}\text { Days to } \\
\text { Discharge }\end{array}$ & $\begin{array}{l}\text { PWB } \\
(\mathbf{w k s})\end{array}$ & $\begin{array}{l}\text { FWB } \\
(\mathbf{w k s})\end{array}$ \\
\hline MVA & $\begin{array}{l}\text { Significant } \\
\text { comminution }\end{array}$ & Head & $\begin{array}{l}3 \text { Units preop } \\
4 \text { Units postop }\end{array}$ & 5.7 & 933 & 156.7 & 7 & 12.5 & 15.3 \\
Falls & $\begin{array}{l}\text { Significant } \\
\text { Comminution }\end{array}$ & Nil & $\begin{array}{l}2 \text { units preop } \\
4 \text { units postop }\end{array}$ & 7 & 1350 & 111.5 & 8 & 8 & 13 \\
Others & $\begin{array}{l}\text { Mild to significant } \\
\text { Comminution }\end{array}$ & Head & 2 units postop & 16 & 1050 & 95 & 6.5 & 9 & 15.5 \\
\hline
\end{tabular}

\section{Discussion}

Musculoskeletal injury secondary to trauma continues to be a major cause of morbidity and mortality in developing countries. ${ }^{7}$ Motor vehicle accidents continue to be the leading cause of trauma. ${ }^{7,8}$ The institute where this study was conducted is located near one of the country's major highways. Thus, motor vehicle accidents always account for a sizable percentage of the admissions. Intramedullary nailing has unquestionably been the treatment of choice for long bone fractures which require surgical care. ${ }^{1,9,10}$ Excellent union rates in combination with low complication rates and excellent return to function has historically made this procedure one of the most successful Orthopaedic surgical procedures. ${ }^{10}$ The ease of insertion and the elimination of the need to pass distal interlocking screws reduce the operation time of the Fixion nail. ${ }^{5}$ Passage of distal interlocking screws remains a potentially challenging, time consuming step when using a device which relies on interlocking screws. ${ }^{11}$ Occasionally force has been used to pass the nail which will then increase the risk of nail damage. ${ }^{5}$ We believe that an anatomic or near anatomic open reduction significantly reduced the force required to pass the nail across the fracture site and hence there were no cases of nail fracture in our series. Blomquist et al. ${ }^{12}$ in his biomechanical study suggested that the expandable nail ought to only be used for stable fracture patterns (greater than $50 \%$ contact between major fragments) as its stability is related to the intrinsic nature of the fracture pattern. It has been argued that shortening is a potential problem if the expandable nail is used in $\mathrm{AO}$ type $\mathrm{C}$ fractures because of reduced cortical contact. ${ }^{1}$ In our study, AO type $\mathrm{C}$ fractures were also successfully treated with the expandable nail, possibly due to the comminuted fragments being circlaged. We theorized that circlaging the fragments may have allowed for adequate cortical contact. Zoccali et al. ${ }^{13}$ stated that for stable fractures, the expandable nail performed well in a head to head comparison with the gold standard interlocked nail. There was no difference in terms of rotational stability and the expandable nail was found to have a higher bending stiffness. Zoccali et al. ${ }^{13}$ also recommended its use only for types A2, A3, B2 and B3. Interestingly, although he performed his procedures closed, the healing times averaged 6 months. He theorized that the high contact pressures produced by expansion of the nail on the endosteum retards healing. Zoccali et al. ${ }^{13}$ considered A1 and B3 contraindications for treatment; however 7 cases of B3 femoral fractures were successfully treated in our study. Ben-Galim et al. ${ }^{1}$ performed a randomized prospective level 2 study in 53 patients with 53 tibial fractures with either an expandable nail or an interlocking nail. The AO/OTA classification in these patients ranged from A1 TO B3. Ben-Galim et al. ${ }^{1}$ concluded that for A1 TO B3 fractures the expandable nail was superior to the interlocking nail. He found a $39 \%$ reduction in overall surgical and hospital cost in the patients treated with the expandable nail. The mean surgical duration was 52.9 minutes in the expandable nail group and 104 minutes in the interlocking group.

To our knowledge, there is no other report in the literature describing open locked nailing using the Fixion nail. Similar to our institution, Sekimpi et al.7 performed open intramedullary locked nailing because their facility did not have fluoroscopy or a fracture table. Similarly they also did not have power reamers. They reported 2 infections (1 superficial, 1 deep), 2 delayed unions, 4 cases of malalignment and zero cases of nonunion and nail breakage. Our operative times did not significantly differ from Kapoor et al. ${ }^{2}$ who performed a closed reduction in 27 out of 32 cases, and our healing times in our lower limb fractures were interestingly superior. The blood loss and surgical time for femoral fracture fixation were actually superior to Lepore's study6 in which he performed his procedures closed. Kapoor et al. ${ }^{2}$ only reported on AO type A and B fractures. Mallik et al. ${ }^{3}$ reported on a high complication rate of 7 complications in 7 patients with acute humeral fractures including 2 nonunion, 2 intraoperative device failures, 2 radial nerve palsies and 1 instance of shoulder pain from proximal nail migration. In Mallik et al. ${ }^{3}$ study, callus appeared at an average of 8.25 weeks and union was at an average of 16.5 weeks. Our study had evidence of advanced callus at 12.3 weeks. Beazley et al. ${ }^{14}$ having performed a Medline search reviewed 2 quazi-randomised studies and 8 case series analyzing the fixation of tibial fracture with the expandable nail. The average reoperation rate was $10.2 \%$, fracture propagation occurred in $2 \%$, the average surgical time was 55 minutes, and the fractures united at an average of 12.2 weeks.

Pascarella et al. ${ }^{15}$ in their review of 19 patients with certain AO type $A$ and $B$ patterns, allowed PWB at an average of 7 days and FWB at an average of 40 days despite achieving consolidation at an average of 5 months for the femur and 4 months in the tibia. This suggests that when appropriate fracture patterns are treated with this implant early weight bearing may be advocated. In any open procedure, the concern will always be an increased infection risk as well as increased risk of a disorder of union due to an exposed fracture site and the loss of a confined fracture haematoma respectively. Time to union in this study 
was similar to those historically reported to close nailing. The single deep infection also correlates favorably with data reported on closed locked nailing. It is our opinion that in hospitals which lack a c-arm, fracture table and power reamers, open locked nailing with the Fixion nail is a viable option.

\section{Conclusion}

We found that open intramedullary nailing had acceptable operative times, healing times, excellent union rates and acceptable complication rates.

\section{Acknowledgment}

Thank you to Dr. Bianca Edwards who was integral in the data collection process.

\section{Conflicts of interest}

The author declares that there is no conflict of interest.

\section{References}

1. Ben -Galim P, Rosenblatt $Y$, Parnes N, et al. Intramedullary fixation of tibial shaft fractures using an expandable nail. Clin Orthop Relat Res. 2007;455:234-240.

2. Kapoor SK, Kataria H, Boruah T, et al. Expandable self -locking nail in the management of closed diaphyseal fractures of femur and tibia. Indian $J$ Orthop. 2009;43(3):264-270.

3. Mallik E, Hazarika S, Assad S, et al. The Fixion nailing system for stabilising diaphyseal fractures of the humerus : A two -year clinical experience. Acta Orthop Belg. 2008;74(3):308-316.

4. Lepore S, Capuano S, Romano G. Preliminary clinical and radiographic results with the Fixion Intramedullary Nail: An inflatable self -locking system for long bone fractures. Folia Traumatologica Lovaniensia. 2011;3:80-85.

5. Panidis G, Sayegh F, Beletsiotis A, et al. The use of an innovative inflatable self locking intramedullary nail in treating and stabilizing long bone fractures. Technique -preliminary results. Osteo Trauma Care. 2003;11:S108-S112.
6. Lepore L, Lepore S, Maffulli N. Intramedullary nailing of the femur with an inflatable self -locking nail: comparison with locked nailing. J Orthop Sci. 2003;8(6):796-801.

7. Sekimpi P, Okike K, Zirkle L, et al. Femoral fracture fixation in developing countries: an evaluation of the Surgical Implant Generation Network (SIGN) intramedullary nail. J Bone Joint Surg Am. 2011;93(19):18111818.

8. Mock C, Cherian MN. The global burden of musculoskeletal injuries: challenges and solutions. Clin Orthop Relat Res. 2008;466(10): 23062316.

9. Bong MR, Kummer FJ, Koval KJ, et al. Intramedullary Nailing of the Lower Extremity: Biomechanics and Biology. J Am Acad Orthop Surg. 2007;15(2): 97-106.

10. Brumback RJ, Virkus WW. Intramedullary nailing of the femur: reamed versus nonreamed. J Am Acad Orthop Surg. 2000;8(2): 83-90.

11. Winquist RA. Locked femoral nailing. J Am Acad Orthop Surg. 1993;1(2):95-105.

12. Blomquist J, Lundberg OJ, Gjerdet NR, et al. Are inflatable nails an alternative to interlocked nails in tibial fractures? Clin Orthop Relat Res. 2008;466(5):1225-1231.

13. Zoccali C, Francesco AD, Ranalletta A, et al. Clinical and radiological midterm results from using the Fixion expandable intramedullary nail in transverse and short oblique fractures of femur and tibia. $J$ Orthop Traumatol. 2008;9(3):123-128.

14. Beazley J, Mauffrey C, Seligson D. Treatment of acute tibial shaft fractures with an expandable nailing system: A systematic review of the literature. Injury. 2011;42(Suppl 4):S11-S16.

15. Pascarella R, Nasta G, Nicolini M, et al. The Fixion nail in the lower limb. Preliminary results. Chir Organi Mov. 2002;87(3): 169-174. 